\title{
¿Socialdemocracia mundial o socialismo de mercado?
}

\author{
Jordi Corominas
}

Resumen

En la actualidad existe una economía capitalista mundial. El análisis de las ciencias sociales advierte que si no hay cambios drásticos en este sistema, puede que nos arroje a una "república de insectos y abrojos, o a un puñado de comunidades sociales humanas heridas y traumatizadas". En tal sentido, se ha ido a la búsqueda de nuevos modelos de organización social. El autor presenta en este artículo una comparación entre dos modelos propuestos por A. Giddens - que propugna la socialdemocracia mundial - y D. Schweickart — que apoya el socialismo de mercado. No defiende a uno ni a otro, sino que intenta explorar con ellos, caminos más allá del orden vigente.

Con la caída de la Unión Soviética y la reorientación de los mecanismos de crecimiento económico en China y otras sociedades comunistas supervivientes, existe una economía capitalista' mundial en un

1. Entiendo por capitalismo un sistema económico de producción de mercancías centrado en la propiedad privada de los medios de producción y del capital, la existencia de un mercado libre (los precios son determinados por la oferta y la demanda con más o menos interferencia del gobierno), y la consideración de la fuerza de trabajo como una mercancía más (la fuerza de trabajo vende su capacidad a aquellos que pueden proveer un lugar de trabajo). El caso de China es una cuestión abierta pero todo parece indicar que se encamina hacia una economía capitalista con un control fuerte del estado sobre industrias estratégicas. El último plan de reestructuración del sector público prevé que la mayoria de empresas públicas sean vendidas para transformarse en empresas privadas o semiprivadas en las que el consejo de administración no tendrá que depender del partido. El Estado conservará 1000 empresas estratégicas. País Internacional, 29 de septiembre, p. 3. 
sentido más completo que nunca. Marx percibió el capitalismo como un monstruo, una manera irracional de conducir el mundo que supedita la satisfacción de las necesidades humanas al mercado, pero un monstruo al fin y al cabo que podía ser domesticado puesto que consideraba que todo lo que ha sido creado por los seres humanos puede someterse a su control. Giddens sugiere una imagen quizás más precisa y más desconcertante: el sistema capitalista mundializado es como el carro de Juggernaut ${ }^{2}$, un dios hindú que cuando es adorado por sus fieles, a veces toma direcciones imprevisibles y los aplasta. Este carro desbocado se puede manejar hasta cierto punto, pero no se puede prever por completo ni el camino que toma, ni el ritmo del viaje; y a su vez, nunca podremos sentimos seguros ni liberarnos de riesgos e incertidumbres fabricados socialmente como holocaustos biológicos o nucleares, o crisis medioambientales. El riesgo creado es un camino sin retorno y con él habrá que contar siempre. En esta imagen ya no podemos aspirar a domesticar al monstruo, sino sólo a ponerle unas riendas que nos permitan dirigirlo de tal manera que minimicemos los peligros y maximicemos las oportunidades para todos.

Las ideas modernas como las que encarno un cierto marxismo popular todavía contaban con que la historia poseía alguna teleología implícita, y con agentes y sujetos privilegiados que de forma más o menos automática acudían a nuestro auxilio para llevarla adelante. Pero hoy no contamos con ningún género de garantías. Las contradicciones descubribles en el análisis de las ciencias sociales en lugar de ofrecernos la promesa de una síntesis más elevada, más bien tienden a advertirnos que el sistema capitalista mundial sin cambios drásticos puede que nos arroje a una "república de insectos y abrojos, o a un puñado de comunidades sociales humanas heridas y traumatizadas". . Ninguna fuerza providencial nos garantiza que esto no suceda. El Apocalipsis se ha convertido en algo tan trivial y familiar, que hasta aburre su letanía.

Pero aunque el sistema capitalista sea un monstruo domesticable o un Juggernaut y por menos garantías y seguridades que tengamos, nada de esto significa que debamos, o podamos, desistir en nuestro intento de domesticar al monstruo o dirigir al Juggernaut. ¿Con qué alternativas contamos que tengan una cierta dosis de realismo, bien por contar con un cierto aval de material empírico o por estar conectadas a ciertas tendencias inmanentes en el sistema actual? La recuperación del carácter contingente de la historia y la imprevisibilidad de la acción humana pueden, en un primer momento, ser desmovilizadoras al lado de las garantías que ofrecen los movimientos proféticos, pero también deja más espacio para la búsqueda de nuevos modelos de organización social. En este sentido, creo que la comparación entre el modelo que propone A. Giddens y el modelo de D. Schweickart ${ }^{4}$ puede brindarnos alguna luz. No se trata de defender a uno o a otro, sino de explorar con ellos caminos más allá del orden vigente. Podría tenerse la tentación de concebir esta comparación como una reactualización del viejo debate entre socialdemócratas o socialistas reformistas y socialistas revolucionarios. Sin embargo, los términos en que ambos autores plantean sus modelos alternativos son tan diferentes respecto a las fórmulas clásicas del socialismo y la socialdemocracia que la comparación confunde en lugar de esclarecer. Si la piedra angular del modelo de Schweickart, la democracia y el mercado, es un tema tabú en el socialismo clásico, la mundialización y la erosión de la nación-estado, tal como las piensa Giddens, son antitéticas con las recetas keynesianas tradicionales.

\section{Inviabilidad de un socialismo de planificación centralizada mundial}

Ambos autores coinciden a grosso modo en su análisis marxista del capitalismo: la plusvalía —el valor del trabajo que deja de pagarse al obrero- es

2. Giddens, A. Más allá de la izquierda y la derecha, El futuro de las políticas radicales, Ed. Cátedra, Madrid, 1996, p. 132.

3. Giddens, A. Ibid, p. 166.

4. De A. Giddens nos referiremos al libro Más allá de la izquierda y la derecha. El futuro de las políticas radicales. Ed. Cátedra, Madrid, 1996; y Las consecuencias de la modernidad, Alianza Universidad, Madrid, 1994. De David Schweickart, Against Capitalism, Westwiew Press, California, 1996. Este mismo mes ha salido la traducción española bajo el título Más allá del capitalismo, Sal Terrae, Santander (España), 1997. También puede consultarse la recensión "La altemativa socialista", ECA, Marzo, 1997, y el artículo de David Schweickart, "Democracia económica. Propuesta para un socialismo eficaz", Realidad, febrero, 1997. 
la principal fuente de acumulación de capital y el secreto de la imposibilidad matemática de hacerse rico trabajando mientras una clase capitalista no involucrada en actividades productivas ${ }^{5}$, puede aumentar exponencialmente sus beneficios. Si el capitalismo ha estado atado durante varios siglos a los estados coloniales y durante este siglo a una fuerte red de régimenes dictatoriales (Somoza, Duvalier, Marcos, Pinochet, Videla y un largo etc.), hoy la élite transnacional del norte y del sur encuentra en la poliarquía ${ }^{6}$ su mejor forma de control político y legitimación social. La poliarquía no es dictadura ni democracia sino un sistema en el cual un pequeño grupo, los poseedores del capital, es el que realmente gobierna, y la participación de la mayoría en la toma de decisiones se limita a elegir entre las élites rivales en competencia en procesos electorales fuertemente controlados. Si aún así los electores salen por peteneras, los poseedores del capital sacan su arma letal: la huelga de inversiones que no suele tardar en provocar la crisis de los gobiernos o su viraje hacia la derecha ${ }^{7}$.

Ambos consideran también que el socialismo de estado conforma una forma de gestión de las empresas económicamente inefectiva y políticamente autoritaria. No se trata sólo del imprevisible elemento subjetivo, o de que los mandos intermedios o no tan intermedios sucumban a la ideología capitalista y a la lógica del interés egoísta, sino de una imposibilidad estructural. El control directivo de la economía puede tener éxito, como creo que muestran fehacientemente los análisis de Giddens ${ }^{8}$, cuando las personas tienen preferencias relativamente estables y cuando su nivel de implicación reflexiva en procesos sociales y económicos más amplios es relativamente bajo. Una economía moderna puede tolerar una gran planificación central, y prosperar con ella, siempre que se trate de una economía nacional, que las influencias universalizadoras no penetren en la vida social en toda su extensión, y

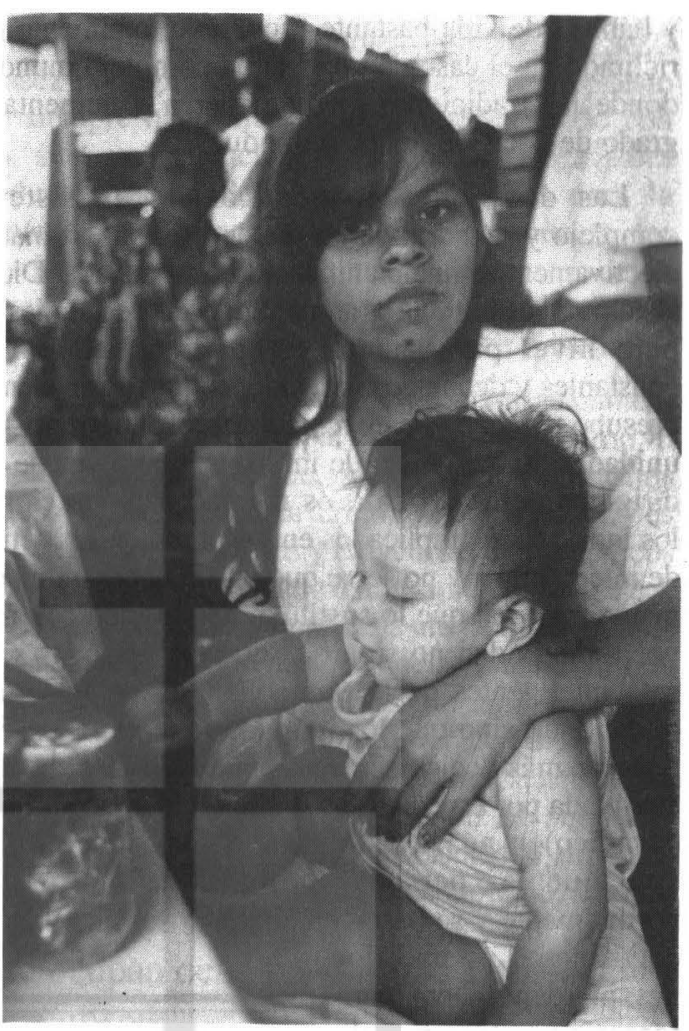

que el grado de capacidad institucional de reflexión no sea demasiado elevado. Cuando estas circunstancias varían, las economías de tipo soviético se estancan. Creo que vale la pena destacar la explicación de Giddens sobre el fracaso del socialismo soviético en función de la mundialización, aunque no sea ni mucho menos el único factor. El socialismo funcionó tolerablemente bien cuando el nivel de universalización y reflexividad social era relativamente bajo. El modelo jerárquico socialista y su subordinación a una inteligencia rectora (estado, vanguardia o partido) parece razonablemente eficaz. para una sociedad con escasa capacidad de reflexión

5. Mientras coordinar trabajo y capital, tarea normalmente encargada a los directores y gerentes de empresas, y trabajar son actividades productivas, proveer capital, es decir permitir usarlo, poner dinero en el banco, comprar acciones, invertir en un mercado de valores y en general las actividades centrales del juego capitalista, no lo son.

6. Robert, Dahl. Polyarchy: participation and Opposition New Haven, Yale, University Press.

7. La existencia de un sistema político poliárquico es, por otra parte, la única explicación plausible de cómo es posible que reinando la democracia por doquier se llegue a tolerar una concentración tan enorme de poder en tan pocas manos. Las impresionantes cifras de la desigualdad pueden constatarse en el informe del PNUD de 1994. Informe sobre el desarrollo humano, 1994, Fondo de Cultura Económica. También el resumen de X. Gorostiaga, "El sistema mundial", Diakonia, No 78, Nicaragua, 1996, p. 12 ss.

8. Giddens, A. Más allá de la izquierd́a y la derecha, Op. cit., p. 153. 
y hábitos de vida bastante fijos, pero totalmente periclitado en el caso de un sistema complejo mundial donde las tradiciones pierden fuerza y aumenta el grado de decisión de los individuos.

Las decisiones económicas en un sistema complejo y mundial ya no pueden ser subordinadas efectivamente a una planificación centralizada. Dicho sistema necesita una gran cantidad de decisiones de bajo nivel para mantener su dinamismo. Los constantes y detallados indicadores que esos sistemas presuponen han de ejercerse sobre el terreno por unidades de bajo nivel de información en vez de ser dirigidos desde arriba. Los mercados proporcionan los indicadores implicados en los complejos sistemas de intercambio, y no se ve que pueda haber un mecanismo mundial que lo sustituya. Un mundo con mayor reflexividad no significa que las personas sean más inteligentes de lo que solían ser en un orden tradicional, sino que los individuos se ven forzados a tomar más decisiones autónomas. La información elaborada por especialistas (incluido el conocimiento científico) ya no puede limitarse a grupos específicos, sino que las personas profanas la interpretan normalmente y se basan en ella para sus actividades cotidianas. Las tradiciones pierden fuerza para forzar una determinada manera de vivir la sexualidad. Los sistemas de comunicación e información actuales suministran tal cantidad de datos que es imposible que sean controlados por una inteligencia rectora y por

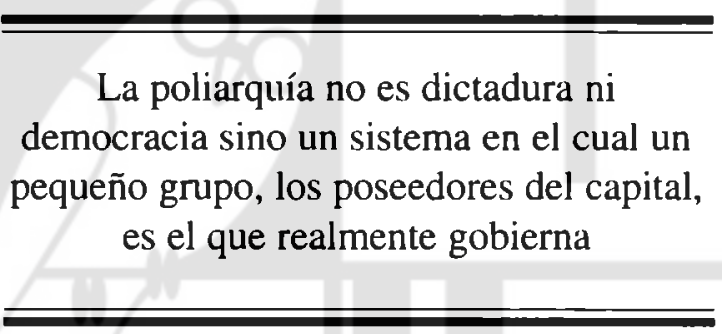

frontera alguna. En definitiva, la necesidad de una mayor reflexividad social destruye los viejos sistemas burocráticos, por más eficientes en la producción e incorruptos que estos sean, y en el terreno de la política, provoca que los estados no pueden ya tratar tan claramente a sus ciudadanos como súbditos".

La simple pretensión de que los mercados capitalistas deben ser regulados para lograr hacer desaparecer de ellos sus cualidades imacionales, nos conduce a un dilema. Sujetar los mercados al control centralizado de un organismo omnicomprensivo no es económicamente eficiente y conduce al auto- ritarismo político. Por otro lado, si se dejan libres los mercados para que operen, más o menos, sin ninguna restricción, se producen cada vez mayores disparidades entre las oportunidades de vida de diferentes grupos y regiones ${ }^{10}$; se causan activamente grandes formas de privación de riqueza, así como la destrucción ecológica y la depauperación y miseria de una gran parte de la humanidad. Podría pensarse que la socialdemocracia es justo la respuesta balanceada o la tercera vía entre un sistema autoritario, pero más justo e igualitario, y un sistema democrático pero cada vez más desigual. Uno de los inconvenientes de la socialdemocracia es que en los países donde se aplica se corrigen más o menos efectivamente, en el interior del estado, las consecuencias más dañinas del sistema, tanto en lo referente a la miseria como a la destrucción ambiental, pero a costa de mantener relaciones de explotación y expolio con otros países. Se le da un rostro humano al capitalismo en casa y se trasladan al exterior sus efectos más perversos.

Otra de las dificultades de las políticas keynesianas, y del llamado estado del bienestar, es que a partir de los setenta entró en los países ricos una crisis aún no resuelta. Una de las causas esgrimida corrientemente para explicar esta crisis es la pérdida de competitividad de las empresas en el mercado mundial debido a la excesiva carga impositiva que representa un estado benefactor. Con la aparición de nuevos e importantes competidores como China y los tigres asiáticos, las industrias, antaño nacionales, sienten la necesidad de neutralizar las interferencias de los estados nacionales en el mercado y de establecer cadenas productivas mundiales.

Por otra parte, si se intentan seguir políticas socialdemócratas en los actuales países pobres, los organismos mundiales y el capital internacional se ocupan de boicotearlas inmediatamente. Cuando existía la Unión Soviética, el impulso de políticas más o menos keynesianas en los países pobres era la fórmula económica para combatir el peligro del

9. Giddens, A. Ibid., p. 95.

10. Como nos comentaba jocoso F. Hinkelammert, si en un cine se levanta uno ve mejor, si se levanta otro también ve mejor, pero si se levantan todos entonces todos ven peor. 
comunismo, pero una vez desaparecido el bloque socialista, la miseria deja de ser una preocupación y un peligro para los intereses del capital. Con el fin de la amenaza "comunista" desaparece también cualquier umbral de tolerancia a la miseria y degradación humana. Sin embargo, esto lo único que prueba es el fracaso de las recetas socialdemócratas en el interior de los estados nacionales cuando estos están insertados en un mercado mundial. ¿No se corregirían precisamente estos problemas si hubiera mecanismos en el ámbito mundial equivalentes a los del estado del bienestar, como elecciones democráticas en organismos mundiales con un fuerte poder (Banco Mundial, Fondo Monetario Internacional, Consejo de Seguridad de la ONU etc.,) impuestos progresivos y obligatorios y servicios e instituciones sociales para los más necesitados? Ya hay ciertamente algunas instituciones mundiales que intentan paliar los problemas de la miseria creciente (FAO, UNICEF, etc.), pero lo hacen por principios de caridad y solidaridad internacional voluntaria. ¿No supondría un cambio drástico que estas instituciones mundiales actuaran con el sentido de obligatoriedad y justicia con que actúan los servicios sociales del estado del bienestar ante sus ciudadanos?

\section{La socialdemocracia mundial}

La alternativa factible para Giddens es justamente una socialdemocracia mundial que implemente políticas de lo que llama bienestar positivo. Lo fundamental de su estrategia consiste en estimular todas aquellas tendencias que fomenten la aparición en el sistema capitalista de un orden post-escasez" ${ }^{\prime \prime}$. La economía post-escasez fue una idea fundamental en algunas versiones del marxismo ${ }^{12}$. La idea marxista de una sociedad post-escasez era la visión de una era de abundancia universal, en la que la escasez desaparecería por completo. En este sentido, es puramente utópica y no ofrece ningún asidero en una situación mundial en la que lo necesario es la conservación de los recursos, y no su desarrollo ilimitado. Tal como lo emplea Giddens, la postescasez no significa la ausencia de escasez puesto que siempre habrá que contar de algún modo con ella, sino una situación en la que los principales productos hayan dejado de ser escasos para la humanidad en su conjunto $y$, en consecuencia, los criterios de mercado únicamente funcionen como aparato indicador de precios, en lugar de ser un medio para concentrar capital y producir miseria ${ }^{13}$.

Mientras que algunos recursos son intrínsecamente escasos (alimentos, ropa, casa), la mayoría no lo es, en el sentido de que, salvo por los requisitos básicos de la existencia corporal, la "escasez" es relativa a las necesidades y exigencias de específicos estilos de vida (саrro, televisión, microondas, etc.). Un orden post-escasez implicaría alteraciones significativas en los modos de vida social y tendrían que modificarse las expectativas de un constante crecimiento económico. Una sociedad mundial post-escasez no significaría una sociedad sin desarrollo económico, sino un sistema en el que ya no regiría el productivismo. Es decir, una sociedad en la que el objetivo de vivir una vida feliz y en armonía con los demás y la naturaleza sería más importante que el trabajo y la producción.

La principal intuición de Giddens es que en un orden post-escasez ya no es necesario crear una autoridad que quite a los ricos para dar a los pobres. No se trata ya de favorecer un reparto riguroso de los bienes materiales que todavía es perfectamente compatible con el productivismo y que por tanto choca, igual que el capitalismo, contra los límites ecológicos, sino del abandono del productivismo y la compulsividad hacia el mismo. Si se consiguen garantizar unos bienes mínimos para todo el mundo estaríamos en condiciones de conquistar una indiferencia hacia el productivismo y la riqueza $y$ desigualdad económica. Si tengo tiempo libre. buenas relaciones afectivas, amigos y mis necesidades cubiertas, ¿para qué voy a desear cambiar esto por

11. Giddens, A. Más allá de la izquierda y la derecha, op. cit., p. 107

12. Véase A. González, “¿Qué queda del socialismo?”. Realidad, enero-febrero, UCA. San Salvador. 1997, p. 15.

13. Giddens, A. Más allá de la izquierda y la derecha, op. cir., p. 181. 
más productividad y consumo, y qué me va a importar que otros tengan mucho más? Sin embargo, esto que parece de sentido común choca con la experiencia. En todas partes parece que muchas personas prefieren consumir y producir más, aún a costa de sacrificar su tiempo libre, sus relaciones afectivas y un relativo bienestar.

Aquí es donde entrarían las políticas de bienestar positivo. Si los estados han tenido grandes éxitos en su lucha contra un hábito tan difícil de erradicar como el hábito de fumar, ¿por qué no esperar que con métodos parecidos se consiga erradicar el hábito compulsivo de consumir y trabajar más y más? Las políticas de bienestar positivo se diferencian de las políticas de bienestar socialdemócratas tradicionales en que éstas ya no pretenden limitarse a curar las heridas después de que sucedan los accidentes, ni van exclusivamente dirigidos a los pobres en forma de subsidios económicos para paliar sus sufrimientos. "El sistema de bienestar positivo se dirige a todos, ricos y pobres y hace mucho más hincapié en el impulso de medidas de política vital que favorezcan la superación de las tendencias compulsivas, y bienes como la seguridad, la realización personal, la felicidad, la liberación de la angustia que son bienes escasos tanto para los ricos como para los pobres y se hallan en peligro debido al espíritu de productividad"14.

Para Giddens no se trata de negar los problemas de los desvalidos, la desmoralización que puede provocar la pobreza y la necesidad de ayuda económica, sino de desarrollar un concepto amplio de bienestar que no suponga sólo ni en primer lugar la idea de la asistencia económica a los desfavorecidos sino, sobre todo, el cultivo de la superación del productivismo, del tiempo libre y de mayores cuotas de satisfacción de la vida y del trabajo. Si el problema principal es el productivismo, las políticas de bienestar positivo deben dirigirse hacia la clase consumidora del mundo, unos 1500 millones de personas, para que aprendan de las solidaridades y la forma de vida de los pobres y de los sectores informales. La connotación inequívocamente negativa del desempleo, cuando éste es subsidiado y no comporta miseria, suele estar relacionada con el carácter compulsivo del trabajo. Este carácter compulsivo varía entre uno y otro sexo y está vinculado a una división de las funciones sexuales que actualmente está cambiando. Las políticas de bienestar positivo deberían promover un mundo en el que los hombres ya no persiguieran tanto el éxito profesional y económico y más, por ejemplo, la comunicación afectiva. Un mundo en el que no fuera sinónimo de fracaso pasar largos períodos sin un trabajo retribuido. Con políticas de bienestar positivo, Giddens considera que los pobres al tener algo que aportar en cuanto a estilos de vida y valores volverían a confiar en sí mismos, a mantener su integridad y responsabilidad social que normalmente se conculcan con los programas de asistencia tradicionales. En definitiva, las fuerzas motoras del bienestar positivo serían la aceptación de la responsabilidad de afrontar los males que el desarrollo ha arrastrado consigo, y la necesidad imperiosa de un cambio en el modo de vida por parte de los privilegiados.

Giddens piensa que este típo de políticas, por más fantásticas y utópicas que nos puedan parecer, tienen cierto fundamento en algunas de las tendencias contemporáneas. Cada vez está más claro que el aumento de la producción y el consumo, una vez alcanzado un cierto nivel, no parece que aumente el grado de felicidad de los privilegiados ni que ofrezca más oportunidades a los desfavorecidos. Para estos últimos, la pobreza se convierte, cada vez más, en fuente de degradación, desintegración social y dependencia de todas clases. Para los más acomodados, el precio será seguramente una angustia creciente, mayores tendencias a la depresión y una existencia fortificada, en la que una mayor prosperidad tendrá un duro precio. Todos los grupos sufrirán los efectos del deterioro medioambiental y los peligros derivados de él. Entre la clase privilegiada consumista mundial empieza a surgir la fatiga del desarrollo, la conciencia de que los procesos de acumulación amenazan o destruyen modos de vida valiosos y de que hay un exceso de desarrollo que produce consecuencias económicas, sociales o culturales inferiores a las deseables.

14. Giddens, A. Ibid., p. 256. 
Los aspectos destructivos del crecimiento económico ilimitado son tan omnipresentes y visibles que ningún estado ni corporación industrial puede ignorarlos. En todo el mundo parece crecer la Una sociedad mundial post-escasez no significaría una sociedad sin desarrollo económico, sino un sistema en el que ya no regiría al productivismo.
Consejo de Seguridad de la ONU, G 7 etc., que cuanto más poderosas menos democráticas son, sería más revolucionaria que una revolución clásica en un estado nacional ${ }^{17}$. sensación de futilidad de unos métodos de desarrollo que se perjudican a sí mismos y destruyen sus propios medios de reproducción. Todo ello hace que por primera vez en la historia ricos y pobres compartan un interés común: "La contaminación del aire, la muerte de los bosques o el despojo estético del medio ambiente no se ajustan a las divisiones de clase. Cualquiera que desee vivir de forma más sana comparte un interés común con los demás frente a una vida que se ha vuelto agria, en la que las ventajas de la riqueza producen, al mismo tiempo, unos efectos perjudiciales que esa riqueza no puede reparar. ¿Qué otra posibilidad existe?"'I5. El sistema no cava ya su propia tumba, como pretendía Marx, sino la tumba de todos.

¿Cuál sería el instrumento social para forjar estas políticas de bienestar positivo lendiente a cambiar el modo de vida de la clase consumidora mundial? Un sistema de post-escasez, incluso si se desarrollara inicialmente en las áreas más ricas del mundo, tendría que ser globalmente coordinado. En algunas formas ya existe una organización económica socializada a escala mundial. Ahí están los acuerdos entre corporaciones transnacionales o gobiernos nacionales que buscan controlar algunos aspectos del flujo internacional de dinero y mercancías ${ }^{16}$. Se trataría en definitiva de someter el capital a algún tipo de planificación democrática que no elimine el mercado y favorezca los intereses de la mayoría de la humanidad.

Como ha sugerido A. González, la democratización de algunas instituciones globales existentes, Fondo Monetario Internacional, Banco Mundial, hecho ver muy bien cómo desde una perspectiva mundial, los principios aparentemente más conven-

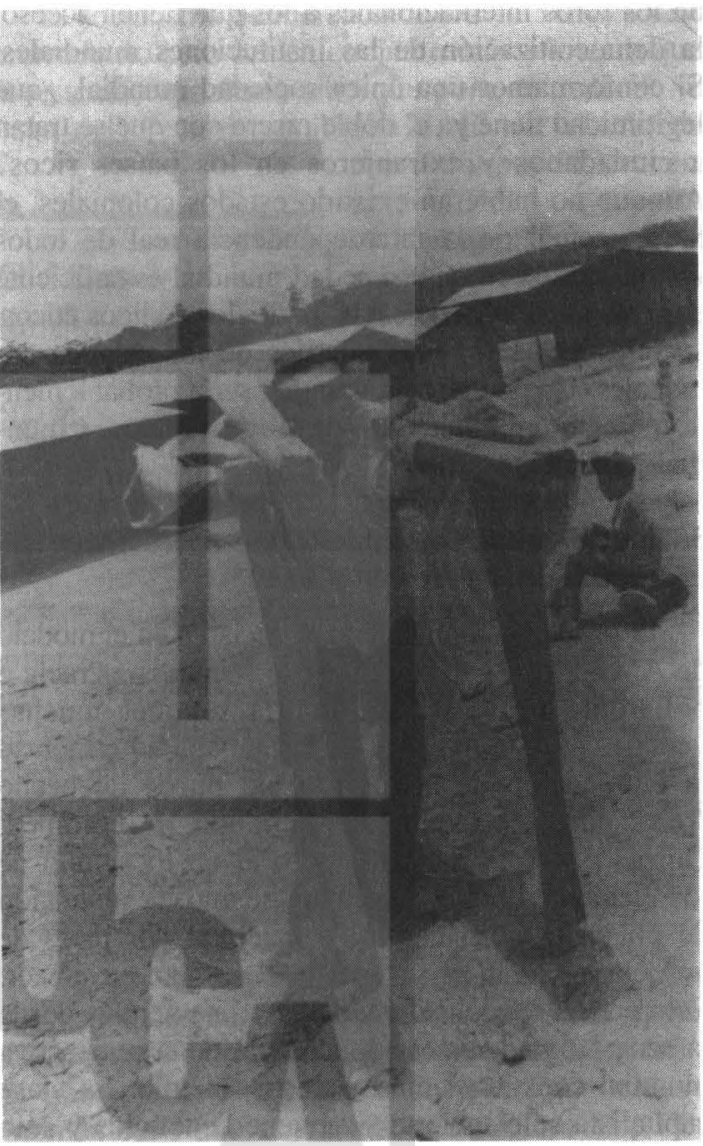

15. Giddens, A. Ibid., p. 203. La quema de 800,000 hectáreas de bosque en Indonesia y el interés en ello de las compañías madereras es un pequeño botón de muestra de la perversidad del sistema.

16. En la última asamblea anual del Banco Mundial y el Fondo Monetario Internacional, realizada el 25 de septiembre de 1997 en Hong-Kong, se aumentó el poder de estas instituciones financieras para que guíen la mundialización de la economía, controlen la comupción y puedan evitar posibles colapsos financieros como los que se están dando en el sudeste asiático.

17. González, A. "Orden mundial y liberación", Revista Diakonía, Boletín del Centro Ignaciano de Latinoamérica, Managua, 1994. Véase también Un solo mundo, Revista Diakonía, No 74, Managua, 1995, y "La transformación de la sociedad mundial", Revista Diakonía, No 78, Managua, 1996. 
cionales y anodinos (democracia, seguridad social, igualdad ante la ley, liberalización económica) adquieren un significado revolucionario que cuestiona el conjunto del orden mundialmente establecido. La paradoja está en que todos estos principios son recomendados por los países ricos a los países pobres pero la sociedad mundial es regida de una manera rigurosamente antidemocrática. Los países que alardean de democracia actúan antidemocráticamente, y países internamente antidemocráticos como Cuba no cejan de pedir, en cualquiera de los foros internacionales a los que tienen acceso, la democratización de las instituciones mundiales. Si conformamos una única sociedad mundial, ¿qué legitimidad tiene ya el doble rasero con que se tratan a ciudadanos y extranjeros en los países ricos? Aunque no hubieran existido estados coloniales, el hecho actual de la interdependencia real de todos los miembros en una sociedad mundial es suficiente para reclamar tales derechos según los códigos éticos, sociales y legales más pueriles de los estados nacionales. Una poliarquía mundial sería probablemente mejor que la dictadura de las instituciones mundiales existentes.

\section{La dificultad insoluble en la socialdemocracia mundial}

El problema a mi entender, decisivo en el modelo de A. Giddens, es el de que esta socialdemocracia o poliarquía mundial, que podría suponer muchas ventajas para la mayoría de la humanidad e incluso la eliminación de la miseria, no puede de hecho frenar la amenaza medioambiental u ecológica. Quizás pueda postergarla, pero al no tocar uno de los elementos básicos del capitalismo, la obtención de plusvalía, y el control del capital por parte de una clase social, el sistema está obligado a crecer. Esto podría ser considerado como una ventaja desde la perspectiva de un estado, pero desde la perspectiva mundial constituye más bien un suicidio. La clase capitalista sólo invierte si obtiene beneficios y sólo obtiene beneficios si hay expansión económica y más productividad. Si no hay crecimiento necesariamente hay crisis, recesión económica y consecuentemente crisis política. En el capitalismo es imposible llegar a un estado de crecimiento estacionario. Con la socialdemocracia mundial moderamos el crecimiento hasta los límites de lo pensable, pero el sistema exige que sigamos creciendo indefinidamente. Aunque D. Schweickart no polemiza con Giddens, de hecho la comparación de su modelo con el capitalismo moderado de $\mathbf{J}$. Rawls y el capitalismo postkeinesiano de Lester - Thurow podría tener también como interlocutor a Giddens $^{1 \mathrm{R}}$. Al comparar ventajas y desventajas entre un capitalismo moderado y un socialismo de mercado, el peso de la balanza se puede inclinar de uno u otro lado cuando consideramos qué modelo favorece más la igualdad, la libertad, la democracia, el pleno empleo, la efíciencia etc., pero el fiel de la balanza se inclina decisivamente hacia el socialismo de mercado cuando ponemos en los platos la cuestión del crecimiento. "Toda forma de capitalismo está estructurada para crecer, necesita crecer y será inestable sin crecimiento"'19.

Aquí creo que D. Schweickart pone el dedo en la llaga central del sistema. Aun asumiendo la hipótesis fantástica de que el sistema capitalista pudiera evolucionar gradualmente hacia un crecimiento cero, llegando a establecer una tasa mínima y más o menos fija de beneficios para los poseedores del capital y de los medios de producción y unos salarios constantes para la mano de obra, es difícil pensar que se pudiera mantener una situación así sin un sistema político autoritario, pues nos encontraríamos de nuevo ante una situación más o menos feudal: una clase de gente vive sin trabajar y otras trabajan indefinidamente sin ningún tipo de mejora en su vida ${ }^{20}$. Dicho de otro modo, el capitalismo para garantizar su estabilidad sin tener que recurrir a la fucrza militar necesita que los que trabajan vayan mejorando siempre, poco importa entonces que los poseedores del capital mejoren mucho más. Pero si los primeros nunca mejoran, la justificación y legitimación de la clase capitalista se complica. No crecer es un suicidio para el sistema capitalista.

Un intento de respuesta a esta objeción consistiría en asegurar que la producción se está desmaterializando, es decir, que necesita cada vez menos de materias primas ${ }^{21}$ y que el desarrollo tecnológico

18. Schweickart, D. "Modern liberalism", Against capitalism, op. cit., p. 242.

19. Schweickart, D. ibid., p. 271.

20. Schweickart, D. ibid., p. 163.

21. Lester Thurow, Head to head, Warner Books, Estados Unidos, 1993. 
nos permitirá pronto aprovechar fuentes de energía no limitadas como la solar y la eólica. Pero aún concediendo esta posibilidad es impensable que podamos crecer ilimitadamente. Primero, porque aunque crezca la producción desmaterializada, la que utiliza recursos no renovables también tiene que seguir creciendo indefinidamente en la economía capitalista y, segundo, porque la producción desmaterializada o la utilización de energías alternativas implica siempre el uso de más y más materias primas (ordenadores, transformadores capaces de transformar la energía solar etc.). Es curioso que se pretenda tan fácilmente volatilizar el uso de recursos naturales y del trabajo (hay quien sueña en fábricas de robots sin trabajadores, como si los robots no los tuviera que fabricar alguien) y que lo más volátil, la clase capitalista dedicada a proveer capital, se considere algo imprescindible. Es conocida la lógica implacable de la paradoja de los chinos. Si cada chino llegara a tener una moto, el mundo reventaría, las emisiones de bióxido de carbono que ocasionarían mil millones

más de motos resquebrajarían el precario equilibrio mundial. Pero no se trata sólo de pensar que el modelo socialdemócrata no sea expandible a Africa, Asia y Latinoamérica, sino de que no es sostenible ni con las fronteras actuales ${ }^{22}$. Si esto es así, es mucho más inconcebible una sociedad mundial que haya desterrado la miseria y el hambre y que crezca indefinidamente. Sólo un economista o un loco pueden creer en la posibilidad de un crecimiento eterno ${ }^{23}$.

Parece sensato suponer que quizás este modelo no soluciona definitivamente el problema neurálgico de la destrucción ecológica, pero al menos sería un paso gigante hacia un cierto control del Juggernaut y podrían plantearse luego transformaciones socialistas más globales que atacaran el mal de raíz, si una socialdemocracia mundial no bastara para ascgurar la sobrevivencia de la humanidad y la naturaleza. Ahora bien, D. Schweickart entenderfa que esto es como pretender curar el dolor de muelas con aspirinas. Si al final tengo necesariamente que ir al doctor, ¿por qué esperar y no empezar ya con el tratamiento? Todo depende, claro está, de que la cura sea eficaz y que el remedio no sea uno de estos potingues para alopecias que acaban por dejarlo a uno más pelón. De esto nos trata de convencer argumentativamente D. Schweickart.

\section{Socialismo de mercado}

El socialismo de mercado de David Schweickart pretende no sólo ser en conjunto más eficiente que el sistema capitalista, sino que pone el dedo en la llaga del crecimiento ilimitado. El socialismo de mercado puede crecer, pero no necesita internamente crecer, puede estabilizarse en un crecimiento cero sin que esto provoque el pánico, la crisis ni la recesión económica gracias a la combinación de un control democrático de las empresas, un mercado libre y un control social de las inversiones. El control democrático de las empresas no se detiene en una participación activa del trabajador, como sugieren diversos teóricos de la gestión empresarial ${ }^{24}$, sino que llega hasta la elección de los gerentes, la organización de centros de trabajo, la exigencia y las pautas de disciplina, la renovación de las técnicas de producción y el establecimiento de las cuotas de producción. Cada trabajador tiene un voto.

En este modelo socialista, el colectivo se reparte los beneficios según un criterio establecido democráticamente y elimina la plusvalía (explotación) y el trabajo como mercancía (enajenación) desde el momento en que el trabajador comparte el poder, los beneficios y los riesgos de la empresa. David Schweickart sugiere un régimen democrático empresarial que sea un punto medio entre el elitismo

22. Según el Word Watch Institute, la sociedad humana apenas tiene 50 años para transformarse radicalmente y garantizar así su supervivencia, L. Brown State of the world, New York, 1990, p. 174.

23. Citado por D. Schweickart en las clases de doctorado de filosofía impartidas en la UCA en octubre de 1997.

24. Peter Drucker, uno de los grandes teónicos de la gestión empresarial, sugiere que las empresas que quieran ser competitivas deberán aprender en el futuro del régimen de gestión participativa de los Boy Scouts. 
tecnocrático japonés y la ineficiencia que suele provocar una democracia directa. El mercado libre se considera imprescindible o insustituible para establecer los precios y el valor de los salarios, con ello se evita la ineficacia de la burocracia, la irracionalidad de la sobrecentralización y la acumulación de poder en una élite. Y, finalmente, el control social de la inversión para frenar la anarquía de la producción capitalista, el poco o nulo incentivo de las cooperativas para crecer y crear nuevas empresas y los desequilibrios entre zonas ricas y pobres se ejerce mediante una planificación del mercado decidida por parlamentos democráticos.

Los fondos de inversión se generan por impuestos sobre los bienes de las empresas (máquinas, instalaciones etc.) y se elimina todo tipo de interés por el dinero. Aquí también se contemplaría una gran flexibilidad de acuerdo con la idiosincrasia cultural. En un extremo habría un conjunto de instituciones basadas en el modelo japonés: una burocracia de élite diseña un plan, y entonces lo aplica rigurosamente, no a la fuerza, sino usando sus amplios poderes en el acceso a las finanzas para frenar algunas empresas $y$ atraer otras para que se desarrollen en las direcciones deseadas. En el otro extremo habría un plan que imitara el resultado del libre mercado, evitando al intermediario capitalista; una especie de laissez-faire socialista. En este caso, el fondo de inversión se reparte proporcionalmente entre unos bancos nacionales, regionales y locales, los cuales ahora lo reparten como subvenciones, exactamente con los mismos criterios que un banco o caja actual. El Parlamento fija el impuesto sobre utilización de bienes (tipo de interés) ajustándolo anualmente para así alinear la oferta del fondo de inversión con la demanda. Este interés se carga a los mismos bancos. A éstos se les permite cargar un tipo de interés más alto en las subvenciones que conceden $y$, así, al intentar maximizar su propio beneficio, corren un riesgo contra el beneficio proyectado del mismo modo en que lo hace un banco capitalista. Bajo este laissez-faire socialista no hay planificación de la composición cualitativa de la inversión, no se intenta incentivar ni desincentivar ninguna línea de producción en particular, ni ningún control consciente sobre la cantidad de inversión ${ }^{25}$.

D. Schweickart sustenta su modelo con importantes datos empíricos, pero sin duda el más significativo es el de las cooperativas Mondragón. Cuando se habla de cooperativas se asocia con pequeñas empresas cuasi familiares y la cuestión que inmediatamente sale a flote es cómo se va a dirigir una multinacional cooperativamente. Esto es lo que nos ejemplifica Mondragón. Una cooperativa pequeña de cocinas de Kerosene, que empezó en 1956 en el país Vasco, se expandió hasta formar en la actualidad, con unas 200 empresas y 25,000 empleados, una de las corporaciones más poderosas del estado español. Las empresas se han diversificado por completo: sus empresas de máquinas cortadoras de metal y de refrigeradores y lavaplatos son los líderes en el mercado español; su caja laboral es considerada entre las cien más eficientes del mundo; su centro de investigación es el único español que ha trabajado directamente con proyectos especiales de la Nasa; sus supermercados se han extendido en España más que cualquier otro; su escuela politécnica con 2000 estudiantes es considerada la mejor del País Vasco; sus tentáculos llegan al Norte de Africa, Oriente medio, China y América Latina, y sus diferencias salariales, el salario más alto es seis veces mayor que el más bajo, es mucho menor que las de las corporaciones capitalistas de tamaño similar. La corporación ha conseguido expandirse en un entorno de caída en picada del empleo ${ }^{26}$ y con muy pocos despidos desde su fundación. Las acciones son de los trabajadores, votan las propuestas de los directivos y cada año eligen a la directiva en asamblea.

Sin embargo, algunos estudios actuales cuestionan muy seriamente "el mito de Mondragón"27:

25. Schweickar, D. "Democracia económica, propuesta para un socialismo eficaz", Realidad, No 55, enero-febrero, 1997, p. 52.

26. Entre 1975 y 1986, el país Vasco perdió 150,000 lugares de trabajo mientras la corporación los aumentaba en 4,500 .

27. Kasmir, Sharryn. The myth of Mondragon: cooperatives, politics, and working-class life in a Basque Town, University of New York Press, 1996. En su encuesta a los trabajadores de Mondragón, el 80 por ciento asegura no reconocer la empresa como suya, casi el mismo porcentaje que se da en las empresas capitalistas privadas. En cambio, la mayoría de los gerentes se siente identificado con la corporación, mientras que la mayoría de los gerentes de empresas privadas no. Kasmir sugiere que el éxito de Mondragón puede deberse al compromiso y entrega de sus 
los trabajadores no sienten que es suya la empresa, se quejan de sentir más presión que en una empresa capitalista y tiene lugar una cierta erosión de la democracia al haberse permitido la contratación temporal y la existencia de empresas en el norte de Africa no regidas democráticamente ${ }^{28}$. Mondragón no es una especie de cooperativa idílica donde todos se consideren como iguales, se sientan felices con su trabajo y participen diariamente en las decisiones. Esto obviamente es un mito. Pero, como argumenta D. Schweickart, lo que no es un mito es su éxito económico. Ello basta para sostener que industrias sin capitalistas pueden ser tan o más eficientes que las empresas tradicionales y competir con ellas en un entorno nada favorable. Que es posible encontrar mecanismos que logren mantener un equilibrio entre la democracia y la autonomía de los gerentes quedando rotundamente desmentida la idea de que una empresa democrática no puede ser eficiente y que la democracia económica es válida para grandes empresas y multinacionales y no sólo para un grupo de amigos.

La diferencia decisiva respecto al modelo de Giddens es que D. Schweickart considera imposible conseguir un capitalismo mundial de rostro humano sin cambiar los elementos esenciales del sistema. El problema es la esencia y la naturaleza del sistema capitalista mismo. Giddens no sólo juzga que ahora es imposible el socialismo sino que incluso si se diera su modelo alternativo pensaría que cualquier avance en una dirección socialista de mercado perjudicaría a los más y beneficiaría a los menos. El socialismo para Giddens, en todas sus formas, ha llegado a su fin. Ahora bien, en la defensa del socialismo no nos anima ninguna voluntad dogmática, de hecho si el sistema capitalista no tuviera nada intrínsecamente que por su propia índole impidiera la satisfacción de las necesidades básicas de la humanidad y la conservación del medio ecológico, renunciaríamos a perder el tiempo pensando en una alternativa socialista. Pero ya hemos esgrimido antes argumentos importantes que nos hacen pensar que esto no es así. Estos argumentos ya no vienen de la izquierda sino de la propia derecha ${ }^{29}$. Ahora bien, ¿qué hace considerar a Giddens inviable y perverso el socialismo de mercado?

\section{Las dificultades del socialismo de mercado}

A. Giddens no duda de que las cooperativas de trabajadores podrían prosperar en algunas circunstancias y durante cierto tiempo. Incluso, considera factible que grandes industrias y multinacionales como Mondragón puedan ser regidas cooperativamente. Sin embargo, estima que este tipo de empresas no puede generalizarse a todo el orden económico porque el capital para ser eficaz, al igual que la mano de obra y los precios, debe someterse de algún modo al mercado. Giddens juzga que si las inversiones y el uso del capital son dirigidos por una burocracia, por más controlados que estén democráticamente, las dificultades creadas en las

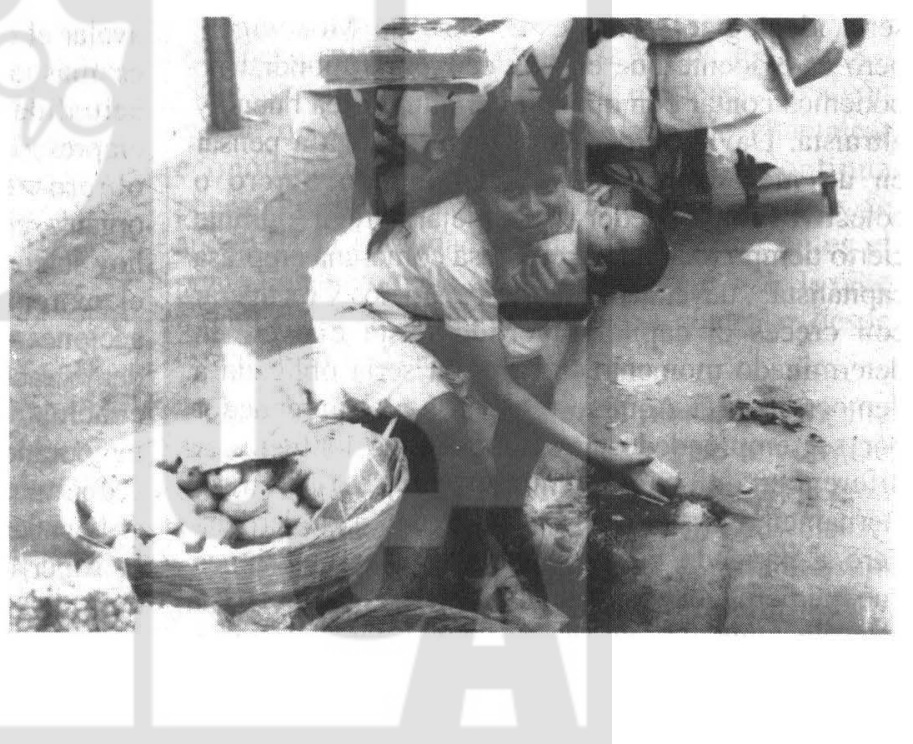

dirigentes y no a la estructura democrática de las cooperativas, pero David Schweickart nos previene de no derivar demasiado rápidamente la conclusión de que los trabajadores son indiferentes a la estructura cooperativa y democrática de la corporación, pues en la misma encuesta de Kasmir sólo el 10 por ciento de los trabajadores preferiría trabajar en una empresa privada.

28. Aquí D. Schweickart esgrime que en un primer momento no se pueden democratizar estas empresas, pero que la voluntad del grupo es de reconvertir paulatinamente su estructura en una estructura democrática.

29. Toffler, A. Powershift, knowledge, wealth, amd violence at the edge of the 21 century, Bantan Books, New York, 1991. 
economías de planificación central volverían a aparecer. No habría criterios ni disciplina de mercado para impulsar el uso real del capital de inversiones acumulado $^{30}$. Por otro lado, sin esta enorme burocracia dirigiendo y controlando las inversiones, el capital almacenado en las empresas tendería a evitar los riesgos y las empresas se estancarían. Habría escasa motivación para contratar a nuevos trabajadores en los colectivos existentes, porque ello reduciría el número de acciones de cada persona y existiría poca movilidad fuera de las cooperativas porque los individuos afectados no podrían llevarse sus participaciones al abandonarlas. De ese modo, el socialismo de mercado mostraría un desempleo estructural masivo, un estancamiento tecnológico, una subasta política de capital caótica y episodios recurrentes de intervención autoritaria por parte del gobierno central para evitar o modificar los abusos de las cooperativas obreras ${ }^{3 !}$.

D. Schweickart prevé estas dificultades. Si las empresas democráticas controlaran absolutamente las inversiones, la economía no se expandiría, pues la inversión en nuevas empresas no produciría beneficios o, en todo caso, el motivo para expandirse sería ideológico, como es el caso de Mondragón, pero es evidente que en una economía mundial no podemos contar con que todo el mundo sea bueno y altruista. David Schweickart incluso llega a pensar en un mecanismo por el cual a todo obrero o colectivo emprendedor se le dejaría regir durante cierto tiempo toda nueva empresa como una empresa capitalista ${ }^{32}$, devengar mayores beneficios y recuperar con creces el capital invertido hasta que en un determinado momento la empresa sería obligada a democratizarse. Aquí se retribuiría al emprendedor por ser emprendedor y sólo mientras lo fuera. A diferencia del capitalismo, no se le retribuiría eternamente por el riesgo y la creatividad ejercida. Pero a parte de las desigualdades y las tensiones que pudiera generar este mecanismo, tampoco se hace ilusiones de que sea suficiente para favorecer la inversión y evitar la contracción económica. Para ello es necesario un control público de las inversiones, y su capital se obtiene, como ya hemos visto, por un impuesto sobre los bienes de uso de la empresa. Parecería entonces que al cambiar una clase parásita capitalista por una clase parásita burocrática mucho mayor, que tampoco está involucrada en actividades productivas, salimos perdiendo en términos de eficiencia en la utilización del capital. Sin embargo, no hay que menospreciar el control democrálico sobre esta burocracia (a diferencia del socialismo de estado) ni sobre todo, como ya hemos visto, que el fondo de inversión obtenido por la recolección de impuestos se puede repartir a los bancos y distribuir con criterios muy semejantes a los del neoliberalismo.

Otro problema que considera fundamental A. Giddens es que la elección periódica de directivos podría tener, en ocasiones, resultados económicos beneficiosos; pero que en la mayoría de las situaciones no sería así. Podríamos abordar la cuestión desde una perspectiva moral y destacar la contradicción de que el capitalismo considere a la gente capaz de elegir a representantes que pueden decidir impuestos, arbitrar leyes y declarar guerras, e incapaz para elegir a sus jefes en el trabajo y tomar decisiones en aquello que más conocen: su propia empresa" ${ }^{\text {", }}$ pero no hace falta. No sólo hay una gran cantidad de material empírico que parece avalar el que la empresa democrática y participativa es más eficaz que la jerárquica sino que, en la actualidad, los grandes teóricos de la gestión empresarial consideran que la participación de los obreros en los objetivos, los beneficios y la organización de la empresa es la clave para mantener hoy su competitividad. Claro está que no llegan hasta el extremo de sugerir la democratización de las acciones de la empresa entre los obreros. Aquí la democracia económica no hace más que derivar las conclusiones que se siguen de las teorías contemporáneas de gestión empresarial. La democracia económica, desde el momento que se introduce en el lugar del trabajo, permite a los problemas salir a la superficie, ser debatidos y resueltos antes que lleguen a un punto crítico. Así, la posible pérdida de liempo en la toma de decisiones democráticas es, en realidad, ganancia para la empresa y siempre se puede mejorar con sistemas democráticos más ágiles.

En la democracia económica es más fácil trabajar con sentido en la medida en que todos están

30. Giddens, A. Más allá de la izquierda y la derecha, op. cit., p. 66.

31. Giddens, A. Ibíd, pp. 76-77.

32. Es lo que de algún modo ya hace Mondragón en las inversiones y las compras de empresas en el Norte de Africa.

33. La contradicción desaparece si consideramos al capitalismo como una poliarquía y no como una democracia. 
involucrados en el desarrollo de la empresa. Las mismas teorías de gestión empresarial reconocen que hoy puede ser más decisivo para la competitividad de la empresa el trabajo con sentido que el mero estímulo económico. Incluso, un autor liberal como $\mathrm{S}$. Mill reconoce que trabajar ciegamente y para el provecho de otros no resulta nunca un estado satisfactorio. Por otro lado, si los estímulos materiales no pueden seguir creciendo eternamente y si el exceso de consumo es para muchas personas causa de soledad, angustia y aburrimiento, las empresas democráticas pueden sustituir más fácilmente este crecimiento por un aumento continuo de la realización personal en el trabajo y del tiempo libre de los trabajadores.

\section{Balance final}

La alternativa socialista de D. Schweickart sale a mi juicio bien librada de las objeciones de $\mathrm{A}$. Giddens al modelo socialista de mercado, pero no lo sale tanto de las objeciones posibles a su esbozo estratégico desde la conceptuación sociológica de la mundialización que realiza este autor. D. Schweickart no parece del todo consciente de las implicaciones económicas del proceso de mundialización y sigue considerando el mundo como una relación entre estados y factible, por tanto, de un socialismo de mercado en un solo estado ${ }^{34}$. La mundialización tal como nos hace ver muy bien Giddens cambia la relación entre el capitalismo y la territorialidad y con ello la relación entre las clases y la naciónestado. Hoy lo que se da es un capitalismo transnacional con una red de instituciones que pasan por alto cada vez más a los estados formales. Los intereses del capital transnacional ya no corresponden con un interés nacional o nación-estado alguno y por ello éstos son reconvertidos en una especie de unidades jurídicas limitadas a lo territorial. En realidad, el capital transnacional y su principal agente institucional, la corporación global, es capaz de aprovecharse de este sistema moderno de naciónestado para arrancarle más concesiones a las clases asalariadas mundiales. Sobre todo en la medida en que la burguesía opera a escala mundial, mientras que las clases asalariadas siguen considerando el estado como la principal y única plataforma de lucha. La separación del mundo en naciones estado genera así una condición central para el poder del capital

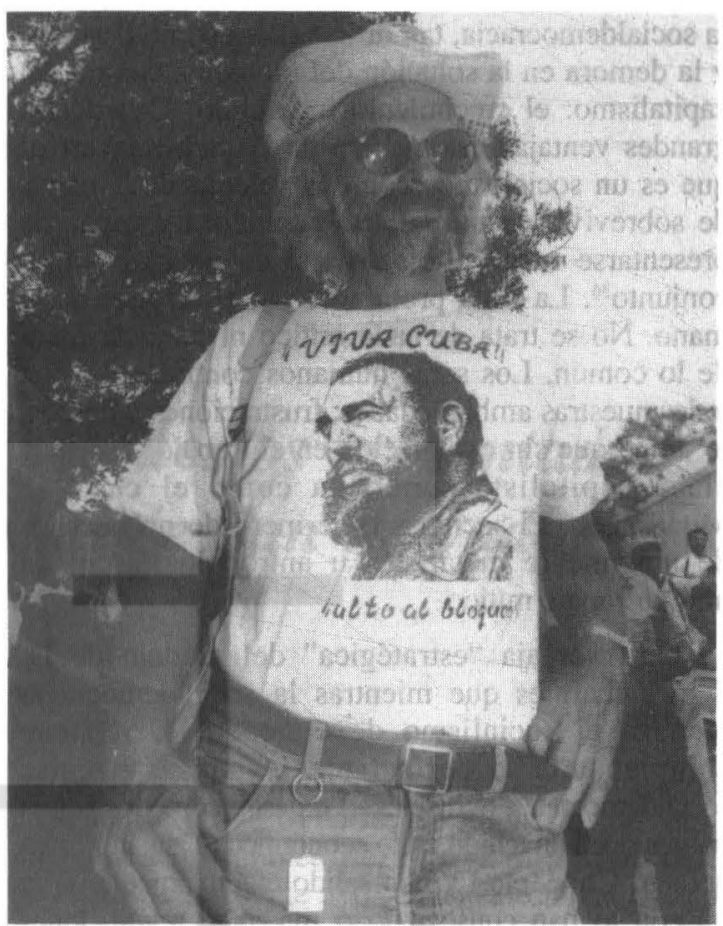

transnacional ${ }^{35}$ que se inmuniza así de toda oposición, exponiéndose a lo más a la existencia de algún estado díscolo fácil, por otra parte, de chantajear económicamente. David Schweickart continua pensando que la nación estado es aún el punto de apoyo de la actividad política pero si éste no es el punto de apoyo de la actividad económica de la élite mundial, no sc ve cómo se pueda controlar desde esta instancia el capital.

Esta crítica afecta no tanto al modelo como a la estrategia de transición. Pero aunque no sea posible un socialismo de mercado en un solo estado, la gran ventaja "estratégica" del modelo de D. Schweickart es que hay espacio en el interior del capitalismo para ir realizando este modelo socialista y coordinarse también transnacionalmente. El socialismo mundial todavía es una meta lejana pero es posible instalarse ya de golpe en él. Se solventa así esta contradicción, no extraña en la izquierda que al desconectar el futuro del presente permite reivindicarse como revolucionario sin afectar el modus vivendi. Por otro lado, se evita una larga transición hacia el socialismo como la que presupone

34. Schweickart, D. Against capitalism, op. cit., p. 274 ss.

35. Robinson, W. "Nueve tesis sobre nuestra época”, Mundialización y liberación, UCA, Managua, 1996, p. 50. 
la socialdemocracia, tan difícil ahora como después, y la demora en la solución del problema central del capitalismo: el crecimiento indefinido. Una de las grandes ventajas del modelo de D. Schweickart es que es un socialismo "con dos velocidades", capaz de sobrevivir en un entorno capitalista y capaz de presentarse como alternativa al capitalismo en su conjunto $^{36}$. La fruta prohibida está al alcance de la mano. No se trata de nada mítico ni de nada fuera de lo común. Los seres humanos continuamos con todas nuestras ambigüedades, frustraciones y deseos, lo único que sin explotación en el trabajo y sin una clase capitalista superflua como el caso de Mondragón. El socialismo de mercado no necesita de ninguna fe metafísica u antropológica, ni de ningún ropaje mítico.

Otra ventaja "estratégica" del modelo de D. Schweickart es que mientras la socialdemocracia rechaza el socialismo de mercado, éste puede complementarse perfectamente con estrategias socialdemócratas. Schweickart muestra cómo los países pobres que han tenido éxito económico (Taiwán, Corea del sur, Chile, etc.) y han salido efectivamente de la miseria lo han conseguido o mediante revoluciones socialistas (Cuba, China) o mediante políticas socialdemócratas: reforma agraria, liquidación de las élites locales, control del capital internacional, severidad con la corrupción, buena educación pública, etc.). No hay ningún ejemplo exitoso de políticas neoliberales en países pobres. Pero lo más curioso es que Estados Unidos siempre que quiso ayudar efectivamente a un país pobre, ya sea para evitar la extensión del comunismo o mostrar que el capitalismo también puede erradicar la miseria, sabía que tenía que desarrollar este tipo de políticas.

Esta complementariedad creo que podría dar salida a un viejo debate de la izquierda latinoamericana. Un sector considera que la raíz de todos los males es el propio sistema capitalista y se oponen a él frontalmente, pero sin tener ahora la alternativa de pasarse al otro bloque que ofrecía la existencia de la Unión Soviética. Otro sector considera que sin alternativa viable a lo que hay que dedicarse es a reformar el sistema para evitar la virulencia de sus peores males. Los primeros tienen razón en considerar el capitalismo intrínsecamente perverso, y los segundos; en la futilidad de una oposición sin propuestas alternativas. Un socialismo de mercado factible a corto, medio y largo plazo abre la posibilidad de aunar ambas posiciones. Por un lado, no necesitamos de una oposición frontal al capitalismo para realizar el socialismo y, por otro, no tenemos por qué aceptar la definitividad del sistema capitalista, ni en el presente ni para siempre.

Los pesimistas pensarán inmediatamente que esta alternativa socialista no puede llevarse a cabo en el actual proceso de mundialización sin un bloque contrahegemónico inteligente y un proyecto popular transnacional. Y aunque llegara a constituirse este bloque, la acumulación de poder militar, tecnológico, político e ideológico del capital es tan abrumador, que tendría escasas posibilidades de victoria. Los optimistas se atreverán a decir que los poseedores de capital no han ganado siempre todas las batallas, ni es tan inusitado en la historia que David venza a Goliat. Sin embargo, sea cual sea nuestro estado de ánimo, y aunque éste suba y baje como la bolsa, lo más destacable es que nunca el sistema capitalista se ha enfrentado como ahora con sus propios límites. Hoy, ni los mismos defensores a ultranza del capitalismo se hacen demasiadas ilusiones respecto a que este sistema pueda proseguir indefinidamente $y$, por tanto, parece que, por primera vez en la historia y en el sentido menos alegórico posible, la victoria total de Goliat sería una derrota universal y la victoria de David la única posible victoria de todos.

36. González, A. “¿Qué queda del socialismo?”, Realidad, op. cit., p. 19. 